\title{
The Market Reaction to Food and Drug Safety Incidents of Listed Companies
}

\author{
Cheng Dai, Chi Xie \\ College of Business Administration, Hunan University, Changsha, Hunan, 410082, China
}

\begin{abstract}
In recent years, food and drug safety incidents of listed companies frequently occur. These incidents were not only bring threat to the life safety of consumers and cause the panic of the society, but also cause disastrous loss to involved companies. In this article, by using incident study method, the abnormal return and cumulative abnormal return of the collector 41 involved companies are analyzed. The empirical results show that involved companies' cumulative abnormal return are significant negative in 35 consecutive trading days after the incidents, and the negative effect lasted until the 120th trading day. The minimum negative cumulative abnormal return is- 0.074 , which means the average value of accumulated loss of the involved companies, is up to $7.4 \%$.

Index Terms - Food safety incident; Drug safety incident; Incident study method; Abnormal return; Cumulative abnormal return
\end{abstract}

\section{Introduction}

In recent years, food and drug safety incidents frequently occurred, "melamine", "poison capsule" and "plasticizer" and other similar incidents continue to occur. Food and drug safety problems are not only relates to people's health and life safety, also let the involved companies suffer huge losses.

Previous studies on food and drug safety incidents, mostly focus on the consumer demand, consumers' perceived risk, purchase intention change and other aspects, but the problem of duration and extent that involved incident suffered have received less attention. In order to solve the above problem, this article through event study method, role to explore the affection of food and drug safety incidents on the involved companies.

\section{Theory and hypothesis}

The food and drug safety incident is a negative social responsibility performance of companies; no doubt these things will bring direct and indirect negative impacts to the involved companies. All these will cause varying degrees of damage to the companies. Salin and Hookerpointed out that the food companies issued a product recall statement, its stock price suffered larger falls[1]. Cheah, Chan and Chieng explore the impact on shareholder wealth of drug manufacturing companies product recall, found that the stock market has a strong reaction to the drug recall statement[2]. Seo, $\mathrm{Li}$ and Almanza studied the influence of food safety incidents of the United States during the past 25 years and found that these firms' stock prices have suffered a significant decline[3]. Cheng and Yin through constructing the model of consumer response to food safety incidents, analyzes consumer responses to food safety incidents[4]. The results showed that the reaction of consumers effected by risk perception; the risk is greater, the response is stronger. Dai, Kong and Wang use Melamine incidents as the background, studied the attitude of investors toward the companies involved, and found that these stocks have emerged fluctuations [5].

When the incident is not too severity, the stock market may not make too big reaction; and if the incident is more severity, investors will not hesitate to sell their shares, caused the price of stocks fallen. At the same time, because of the information with a delay in the process of communication, the information content and each Communication is no integrity, which is likely to make the market ineffectively respond in a short period of time. Thus, this paper set a longer incident window, and puts forward the following assumptions:

Hypothesis: The market will have a negative reaction, and lasts for a period of time to the involved companies in food and drug safety incidents.

\section{Research design}

\section{A. The empirical method}

The method of event study method has been widely used in the assessment of a specific incident impact on companies stock returns. Using event study method need to calculate abnormal returns (Abnormal Return, AR). This is a representation of the real return minus the expected return (Expected Return, ER) of the incident window period. Cumulative abnormal return (Cumulative Abnormal Return, CAR) represents the cumulative impact of incidents. Studies have shown that, the initial dissemination of information has been provided to the investors of all complete information, so that investors can not accurately estimate the overall impact of incidents. Therefore, a relatively long incident window selected to explore the effect of duration of the incident. In the empirical process of concrete, this paper carries on the $\mathrm{T}$ test of the data through the SPSS16.0, in order to determine the abnormal return or cumulative abnormal returns are significantly different from 0 .

In this paper, the abnormal return and cumulative abnormal return of the specific indicators of the calculation process is as follows:

1) The $i$ companies stock return. This paper use differential logarithmic calculate it, $R_{i, t}$ express the return of $i$ companies stock in the $t$ days of; $P_{i, t}$ express the closing price of companies $i$ stock in the $t$ days :

$$
R_{i, t}=\ln \left(p_{i, t}\right)-\ln \left(p_{i, t-1}\right)
$$


2) The constant term and the return coefficient of market. In this paper, through the Market Model to calculate them, $R_{m, t}$ mean the market return of $t$ day; $\alpha_{i}$ is constant; $\beta_{i}$ is the return coefficient of market. The estimation window specific as 250 trading days before incidents occurred, that is $\left[\mathrm{t}_{-255}, \mathrm{t}_{-5}\right]$. $\varepsilon_{i, t}$ is a random error term:

$$
R_{i, t}=\alpha_{i}+\beta_{i} * R_{m, t}+\varepsilon_{i, t}
$$

3) The rate of Expected Return (ER). Companies rate of expected return by equation (3) to get:

$$
E R_{i, t}=\alpha_{i}+\beta_{i} * R_{m, t}
$$

4) Abnormal Return (AR) and Cumulative Abnormal Return (CAR). The rate of return abnormal is caused by companies' specific incidents, which is real rate of return minus the rate of expected return.

$$
A R_{i, t}=R_{i, t}-E R_{i, t}
$$

Based on AR, the companies $i$ cumulative abnormal returns during the incident window rate:

$$
C A R_{i, t}=\sum_{t=0}^{t=t} A R_{i, t}
$$

\section{B. Sample selection and data sources}

This paper collected sample that have occurred food and drug safety incidents from 2008(chose 2008 as the starting point source is the "melamine incident" occurred in this year, Cause great panic in society, and thus gave birth to the "food safety law"), delete the following sample during the study period: the occurrence of major litigation cases, severe lack of transaction data and non SZ or SH shares of listed companies and the ST (Special Treatment) or PT (Particular Transfer) companies in the incident window period. Finally, the study sample consists of 41 companies. Firms' daily stock price and the rate of return market are from CSMAR database.

\section{Empirical results and analysis}

Table 1 shows abnormal return rate of sample companies after the incident. Negative abnormal returns and cumulative abnormal return rate indicates that the companies have been negatively impact by the incidents. $T$ test was used to analyze the abnormal return and cumulative abnormal returns are significantly different from 0 . In Table $1, \mathrm{P}$ values shown, in 0th, 1th, 2th, 4th, 6th, 10th trading day appeared negative significant abnormal returns rate, showed that the market rapidly given punishment to the companies involved after the incident.
Table1. abnormal return of the companies involved

\begin{tabular}{|c|c|c|c|c|}
\hline Day & Mean & S.D. & T value & P value \\
\hline$t_{-5}$ & -0.001 & 0.015 & -0.454 & 0.653 \\
\hline$t_{-4}$ & 0.004 & 0.017 & 1.376 & 0.176 \\
\hline$t_{-3}$ & 0.006 & 0.028 & 1.396 & 0.170 \\
\hline$t_{-2}$ & 0.010 & 0.025 & 2.627 & $0.012^{* *}$ \\
\hline$t_{-1}$ & 0.003 & 0.014 & 1.211 & 0.233 \\
\hline$t_{0}$ & -0.013 & 0.031 & -2.766 & $0.009^{* * *}$ \\
\hline$t_{1}$ & -0.015 & 0.042 & -2.221 & $0.032^{* *}$ \\
\hline$t_{2}$ & -0.008 & 0.031 & -1.736 & $0.090^{*}$ \\
\hline$t_{3}$ & 0.0003 & 0.036 & 0.049 & 0.961 \\
\hline$t_{4}$ & -0.008 & 0.027 & -1.976 & $0.055^{*}$ \\
\hline$t_{5}$ & 0.0004 & 0.027 & 0.104 & 0.918 \\
\hline$t_{6}$ & -0.014 & 0.030 & -3.010 & $0.005^{* * *}$ \\
\hline$t_{7}$ & 0.006 & 0.038 & 1.091 & 0.282 \\
\hline$t_{8}$ & 0.002 & 0.021 & 0.689 & 0.495 \\
\hline$t_{9}$ & -0.004 & 0.022 & -1.117 & 0.271 \\
\hline$t_{10}$ & -0.008 & 0.025 & -1.923 & $0.062^{*}$ \\
\hline
\end{tabular}

Note: $1 . t_{\mathrm{n}}$ means the trading day after the incident; $2{ }^{*} \mathrm{p}<0.1,{ }^{*} \mathrm{p}<0.05$, $* * * \mathrm{p}<0.01$; the same below.

Cumulative abnormal return reflects the effect of duration of incidents on the companies and the accumulated results. Conclusion can be drawn from data of table 2 , in the 35 consecutive trading day, cumulative abnormal return is always negative, the negative cumulative abnormal returns are still in the 120th trading day after the incident outbreak. Then, rate of cumulative abnormal returns gradually transformed into the positive. This means, the companies took almost half a year (there are 250 trading days in a year) to recovered from the incident. Therefore, the comprehensive table 1 , table 2 gives the results can prove the hypothesis.

Table2. cumulative abnormal return of the companies involved

\begin{tabular}{|c|c|c|c|c|}
\hline Day & Mean & S.D. & T value & P value \\
\hline$t_{0}-t_{1}$ & -0.028 & 0.054 & -3.303 & $0.002^{* * *}$ \\
\hline$t_{0}-t_{2}$ & -0.036 & 0.076 & -3.091 & $0.004^{* * *}$ \\
\hline$t_{0}-t_{3}$ & -0.036 & 0.092 & -2.528 & $0.015^{* *}$ \\
\hline$t_{0}-t_{4}$ & -0.044 & 0.106 & -2.707 & $0.010^{* * *}$ \\
\hline$t_{0}-t_{5}$ & -0.044 & 0.110 & -2.580 & $0.014^{* *}$ \\
\hline$\ldots$ & & & & \\
\hline$t_{0}-t_{10}$ & -0.061 & 0.111 & -3.528 & $0.001^{* * *}$ \\
\hline$\ldots$ & & & & \\
\hline$t_{0}-t_{20}$ & -0.062 & 0.191 & -2.106 & $0.041^{* *}$ \\
\hline$\ldots$ & & & & \\
\hline$t_{0}-t_{30}$ & -0.069 & 0.195 & -2.253 & $0.030^{* *}$ \\
\hline$\ldots$ & & & & \\
\hline$t_{0}-t_{33}$ & -0.065 & 0.197 & -2.118 & $0.040^{* *}$ \\
\hline$t_{0}-t_{34}$ & -0.066 & 0.202 & -2.093 & $0.043^{* *}$ \\
\hline$t_{0}-t_{35}$ & -0.060 & 0.209 & -1.847 & $0.072^{*}$ \\
\hline$\ldots$ & & & & \\
\hline$t_{0}-t_{119}$ & -0.011 & 0.409 & -0.152 & 0.880 \\
\hline$t_{0}-t_{120}$ & -0.017 & 0.404 & -0.248 & 0.806 \\
\hline$t_{0}-t_{121}$ & 0.029 & 0.319 & 0.535 & 0.597 \\
\hline$t_{0}-t_{122}$ & 0.029 & 0.320 & 0.531 & 0.599 \\
\hline & & & & \\
\hline
\end{tabular}




\section{Conclusion}

It is clear that food safety events have negative impacts on food related firms. However, how serious the events are and how long the negative impact usually lasts has not been examined in the hospitality academia. The paper provides evidence of the extent and duration that the effect of food and drug safety incidents on the companies involved from the empirical perspective. Through the specific course of the study found that the companies suffered significant negative abnormal returns at the outbreak day of incident and 1th, 2th, 4th, 6th, 10th trading days. In the 35 consecutive trading day, cumulative abnormal return is always negative, the negative cumulative abnormal returns are still in the 120th trading day after the incident outbreak.

\section{Acknowledgment}

This work was financially supported by the National Natural Science Foundation of China (71373072), the Foundation for Innovative Research Groups of the National Natural Science Foundation of China (71221001) and the
National Soft Science Research Project of China (2010GXS5B141).

\section{References}

[1] Salin V and Hooker N H, "Stock market reaction to food recalls," Review of Agricultural Economics, vol. 23, no. 01, pp. 33-46, April 2001.

[2] Cheah E T, Chan W L and Chieng C L L, "The corporate social responsibility of pharmaceutical product recalls: an empirical examination of U.S. and U.K. markets," Journal of Business Ethics, vol. 76, no. 4, December 2007.

[3] Seo S, Li M and Almanza B, "Risk communication on restaurant associated food safety incidents: an examination of media coverage of restaurant-associated food safety incidents and its impact on stock price of restaurant firms," Scholar Works, UMASS AMHERST, January 2011.

[4] Cheng P G and Yin Z Y, "Risk perception, risk preference, and response of consumers to food safety crisis: the case of the Clenbuterol Pork," Management Review, vol. 24, no. 12, pp. 128-136, March 2012.

[5] Dai Y H, Kong D M and Wang M B, "Investor reactions to food safety incidents: evidence from the Chinese milk industry," Food Policy, no. 43, pp. 23-31, June 2013. 